\title{
Investigation of coking diesel injector spray nozzles in operation
}

\author{
Aslan Apazhev, Yuri Shekikhachev", Vladimir Batyrov, Lyudmila Shekikhacheva, and \\ Anzor Bolotokov
}

Kabardino-Balkarian State Agricultural University named after V.M.Kokov, 360030, Lenin Avenue, 1V, 360030 Nalchik, Russia

\begin{abstract}
One of the significant problems in ensuring the reliable operation of the nozzles is the intensive coking of the injector spray nozzle ports. Based on the assumption that all fuel left by injection under the needle burns, some researchers believe that the reason for coking is insufficiently emptying of this volume. There is also a well-known opinion about the impact of atomization quality at the final phase of injection. The lack of consensus and conflicting recommendations on the issue make the research relevant. A set of investigations has been carried out at OJSC "TsNITA" to study the influence of various factors, including design factors of the fuel system, on the coking of injector spray nozzle ports. This article describes the investigation results carried out on the basis of test materials for 24 variants of fuel systems on the D-240 engine, the analysis of varying parameters for the injection final phase is carried out depending on the combination of design factors and the relationship of coking of the injector spray nozzle ports with the final phase parameters is shown.
\end{abstract}

\section{Introduction}

During the injection process, coking occurs in the injector spray nozzle ports, even in the absence of visible violations of the fuel supply process (leaks, afterinjection, etc.). In scientific circles, there is no consensus on the causes of coking, recommendations are contradictory.

Some researchers suggest that the cause of coking is partial or complete emptying of the nozzle ports and the volume under the needle, causing the penetration of cylinder gases and oxidation of the remaining fuel film [1 3 ].

Reducing coking of sprayers at the final phase of injection is possible due to [4-7]: increasing the stroke of the needle and the diameter of its shut-off cone; reducing the density in the precision sprayer couple; reducing the area of the spray ports; reducing the stroke of the needle and its shut-off cone diameter. As a criterion for coking of the spray ports, the duration of the needle fit is often taken [8-15]. There is no experimental confirmation for the dependence of coking on the fuel equipment structural elements and

\footnotetext{
* Corresponding author: shek-fmep@mail.ru
} 
the parameters of the fuel supply process, as well as the amount of fuel in the volume under the needle after injection.

\section{Materials and methods}

Tests on engines and a non-motorized bench were carried out only at the mode corresponding to the maximum torque. During oscillography of the fuel supply process, the injection was carried out into the bomb with an air back pressure of $5.0 \mathrm{MPa}$. All experiments were carried out on the same fuel delivery. The influence of the sprayer sizes was excluded by using one set of sprayers in the entire series of experiments.

\section{Results and discussion}

The coking degree of nozzle ports was determined by spilling nozzles out of a needle on a constant feed bench and was calculated by the formula:

$$
k=\frac{\mu f_{1}-\mu f_{2}}{\mu f_{1}},
$$

where $\mu f_{1}$ is the effective flow passage of the nozzle ports before the experiment, $\mathrm{mm}^{2}$; $\mu f_{2}$ is the effective flow passage of the nozzle ports after the experiment, $\mathrm{mm}^{2}$.

The dependence of the coking of the injector spray nozzle ports on the needle maximum stroke and the discharge volume of the pressure valve (Fig. 1) shows that the influence of the investigated design factors on coking is differentiated depending on their value.

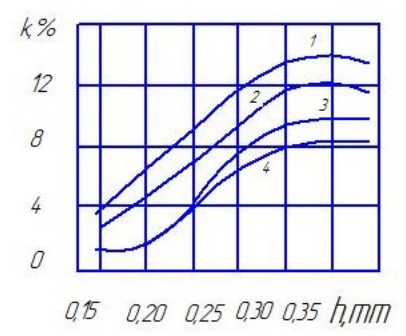

Fig. 1. Dependence of coking of the injector spray nozzle ports $(k)$ on the needle stroke $(h)$ and the discharge volume of the pressure valve $\left(V_{r}\right)\left(1-V_{r}=35 \mathrm{~mm}^{3} ; 2-V_{r}=50 \mathrm{~mm}^{3} ; 3-V_{r}=65 \mathrm{~mm}^{3}\right.$; $4-V_{r}=80 \mathrm{~mm}^{3}$.

In principle, an increase in the needle travel up to $0.35 \mathrm{~mm}$ contributes to the intensification of coking with all the investigated valves. With a decrease in the needle stroke, the influence of the valve weakens. It also follows from the results received that the same amount of coking can be obtained by a different combination of the needle stroke size and the discharge volume of the pressure valve. This indicates that the structural elements do not affect the coking of the nozzle ports directly through the structure, but due to the parameters of the fuel supply working process. Various combinations of the fuel system structural elements change the process of fuel supply, regulate the "time - section" value in the sprayer, and control the state of the fuel at the final phase.

Of the list of parameters (time, pressure) that determine the final phase of the fuel supply process, the parameter is directly related to the intensity of coking of the nozzle ports: 


$$
\lambda=\frac{P_{a}}{P_{\varphi}-P_{a}},
$$

where $P_{a}$ is the pressure in the "appendix", $\mathrm{MPa} ; P_{\varphi}$ is the pressure above the cone, $\mathrm{MPa}$.

The ratio $\lambda$ characterizes the dynamics of the fuel flow in the section of the flowing part of the sprayer inlet to the cone - "appendix".

The curve $k=f(\lambda)$ shows the dependence of the intensity of coking the sprayers on the parameter $\lambda$ for all the variants of the fuel system of the D-240 engine under investigation, an increase $\lambda$ facilitates mitigation of coking (Fig. 2).

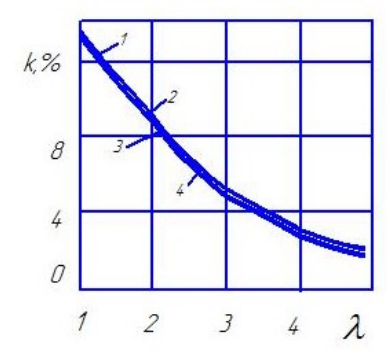

Fig. 2. Dependence of coking the injector spray nozzle ports $(k)$ on the dynamics of the fuel flow $\lambda$ at $(h=0.2-0.35 \mathrm{~mm}): 1-V_{r}=35 \mathrm{~mm}^{3} ; 2-V_{r}=50 \mathrm{~mm}^{3} ; 3-V_{r}=65 \mathrm{~mm}^{3} ; 4-V_{r}=80 \mathrm{~mm}^{3}$.

An exception is the fuel system variants with a discharge volume of the pressure valve of $80 \mathrm{~mm}^{3}$ and a needle stroke of more than $0.3 \mathrm{~mm}$, for which coking increases (in comparison with $V_{r}=65 \mathrm{~mm}^{3}$ and $h=0.3 \mathrm{~mm}$ ) due to the gases penetration into the sprayer due to the "overturning" of the fuel flow.

Thus, the influence of the investigated structural elements of the fuel equipment concerning coking the injector spray nozzle ports is carried out through the process of fuel supply by changing the operating mode of the sprayer at the final phase of injection.

The strongest effect on the parameters of the fuel supply process, and, consequently, the coking the injector spray nozzle ports is occurred by limiting the needle stroke to the value of $h=0.15-0.2 \mathrm{~mm}$ which helps to stabilize the fuel pressure drop across the cone during its fitting (Fig. 3)

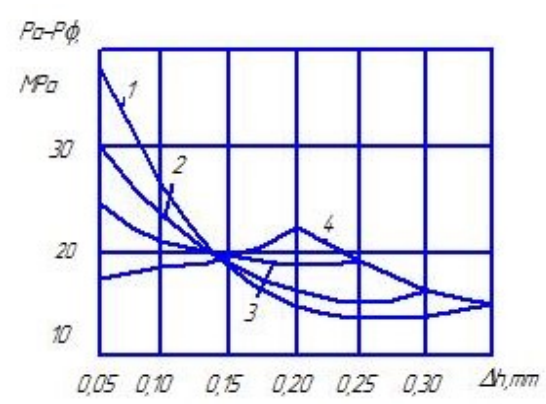

Fig. 3. Dependence of pressure drops across the nozzle cone at the final injection phase of the needle position $\left(V_{r}=35 \mathrm{~mm}^{3}\right): 1-h=0.2 \mathrm{~mm} ; 2-h=0.3 \mathrm{~mm} ; 3-h=0.25 \mathrm{~mm} ; 4-h=0.35 \mathrm{~mm}$. 
The specified stroke can be achieved by increasing the outlet section of the cone by increasing the diameter of the central channel under the needle.

Investigations carried out at JSC "TsNITA" on engines D-60, D-240, D-37E and AM-01 showed that an increase in the central channel under the needle to $1.6 \mathrm{~mm}$ with a simultaneous decrease of the needle stroke to $h=0.18-0.25 \mathrm{~mm}$ contributes to reducing the level of coking to a safe value $(k=1-2 \%)$ [1-3].

Analysis of the test results (Fig. 4) indicates that the general regularity between the intensity of coking the injector spray nozzle ports and the time of the needle fitting at the final phase is not observed for all variants of diesel fuel systems.

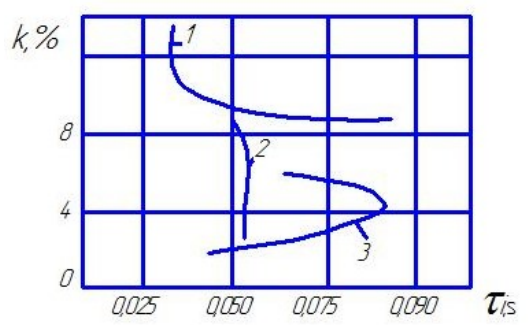

Fig. 4. Dependence of coking the nozzle ports from the time of needle fitting in position $\tau_{i}=0.05$ $\mathrm{mm}: 1-h=0.35 \mathrm{~mm} ; 2-h=0.25 \mathrm{~mm} ; 3-h=0.2 \mathrm{~mm}$.

Depending on the system packaging, the influence of the fitting speed is differentiated. The duration of the needle fitting at the final phase, together with the discharge volume of the pressure valve and other structural elements of the fuel system, determines the rate of decrease in fuel pressure above and below the cone, i.e., it changes the value of the fuel pressure drop across the cone and, therefore, regulates the fuel flow rate.

\section{Conclusions}

The parameters $\left(V_{r}, h\right)$ of the diesel fuel system regulate the ratio of the operating parameters for the final phase of fuel injection, and also significantly affect the intensity of coking the diesel injector spray nozzle ports. Limiting the needle stroke to $h=0.15-0.2 \mathrm{~mm}$ in the examined variants of the system makes it possible to stabilize the pressure drops on the cone at a minimum level and to reduce coking the nozzle ports to an acceptable value.

\section{References}

1. V. S. Koichev, A. K Kobozev, I. I. Shvetsov, D. I. Gritsai, E.V. Gerasimov, J. of Pharmac., Biolog. and Chemic. Sci., 8(5), 642 (2017)

2. V. Coichev, K. Mosikyan, News of the National Agr. Univ. of Armenia 3, 44 (2016)

3. V. S. Kurasov, V. V. Dragulenko, S. M. Sidorenko, Theory of internal combustion engines (2013)

4. A. K Apazhev, Y. A. Shekikhachev, V. I. Batyrov, L. Z. Shekikhacheva, J. of Phys.: Conf. Ser. (JPCS), 1679, 042063 (2020)

5. A. K Apazhev, Y. A. Shekikhachev, V. I. Batyrov, Kh. L. Gubzhokov, A. L. Bolotokov, IOP Conf. Ser.: Mater. Sci. and Engin., 663(1), 012049 (2019)

6. Y. A. Shekikhachev, R. A. Balkarov, M. M. Chechenov, H.B. Kardanov, L. Z. Shekikhacheva, J. of Phys.: Conf. Ser., 1515(4), 042029 (2020) 
7. Yu. A. Shekikhachev, V. I. Batyrov, R. A. Balkarov, L. Z. Shekikhacheva, Kh. L. Gubzhokov, Tech. and equip. for the vill., 4(262), 14 (2019)

8. F. Kh. Khaliullin, A. V. Matyashin, R. R. Akhmetzyanov, V. M. Medvedev, M. A. Lushnov, IOP Conf. Ser.: Mater.s Sci. and Engin. Electr. Coll., 012016 (2019)

9. S. A. Sinitsky, V. M. Medvedev, R. R. Lukmanov, G. V. Pikmullin, O. I. Makarova, BIO Web of Conf. Internat. Sci.-Pract. Conf., 00025 (2020)

10. V. S. Koichev, K. A. Mosikyan, M. S. Barseghyan, Problems of scientific and technological progress in the agro-industrial complex (2017)

11. V. S. Kurasov, V. N. Pleshakov, E. E. Samurganov, A. V. Ponomarev, Proceed. of the Kuban St. Agr. Univ., 58, 315

12. A. K Kobozev, I. I. Shvetsov, V. S. Koichev, I. I. Gazizov, N. V. Bakholdin, Improvement of scientific and methodological work at the university (2018)

13. A. K Kobozev, I. I. Shvetsov, V. S. Koichev, Topical issues of engineering education (2016)

14. A. K Kobozev, I. I. Shvetsov, V. S. Koichev, Topical issues of engineering education (2016)

15. B. L. Ivanov, B. G. Ziganshin, R. F. Sharafeev, I. R. Sagbiev, Bull. of Kazan St. Agr. Univ., 14, 95 (2019) 